\title{
IGG4-RELATED DISEASE PRESENTING AS PACHYMENINGITIS IN A PATIENT WITH SYSTEMIC LUPUS ERYTHEMATOSUS: CASE REPORT
}

Giovanny Homero Jacome Verdugo ${ }^{1, *}$, Lorena Elizabeth Betancourt Villamarin ${ }^{1}$, Karina Fernanda Pucha Anguinsaca ${ }^{1}$, Henrique Ayres Mayrink Giardini ${ }^{1}$, Rosa Maria Rodrigues Pereira ${ }^{1}$

1. Universidade de São Paulo, São Paulo (SP), Brazil.

*Corresponding author: giova.jacome9@gmail.com

\section{BACKGROUND}

IgG4-related disease (IgG4-RD) is an immune-mediated fibroinflammatory condition that can affect multiple organs. Central neurologic manifestations are rare with reports of mostly hypophysitis and hypertrophic pachymeningitis. Diagnosis is histologic and shows lymphoplasmacytic infiltration with lgG4+ plasma cell proliferation, storiform fibrosis, and obliterative phlebitis. Glucocorticoids form the basis of treatment.

\section{CASE REPORT}

A 57 years old white woman with a 10 years history of systemic lupus erythematosus (SLE), in remission, with current use of hydroxychloroquine. The patient came for routine evaluation with a complaint of bifrontal headache associated with binocular diplopia and reduced visual acuity in the right eye for 6 months. In addition, she referred bilateral hypoacusis in the last three months. The physical examination revealed facial hypoesthesia. Campimetry showed central/centrocecal scotoma in the right eye. Cranial and orbital magnetic resonance imaging revealed areas of anomalous gadolinium impregnation in the pachymeningeal compartment, notably in the right frontobasal and temporal regions, including extending to the orbital apex, cavernous sinus, foramina of the skull and inferiorly through the pterygopalatine fossa until posterior wall of the right maxillary sinus, associated with alteration of the sign of the underlying brain parenchyma. The histopathological study after meningeal and orbital biopsy disclosed chronic inflammation with plasma cells. The lgG4+/lgG ratio was $40 \%$ confirming the diagnosis of IgG4-RD. The patient had a favorable evolution with azathioprine e glucocorticoids.

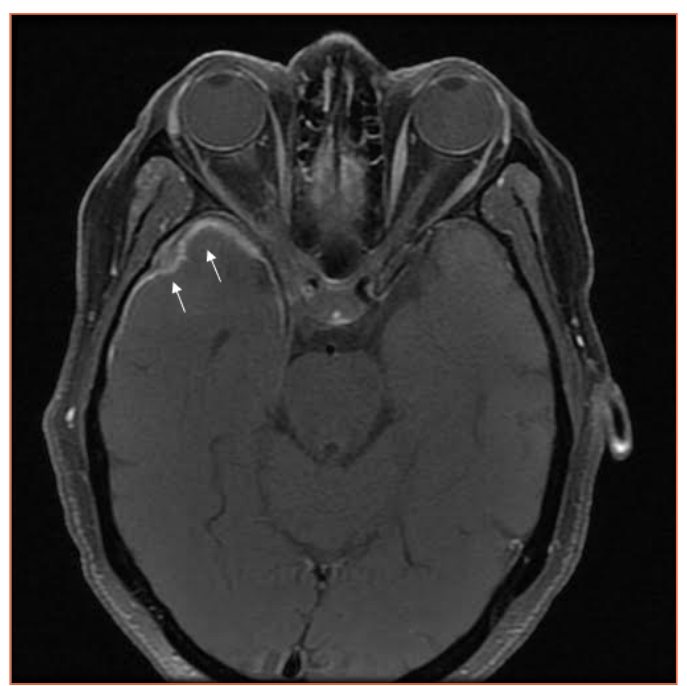

Figure 1. MRI of brain axial view. 


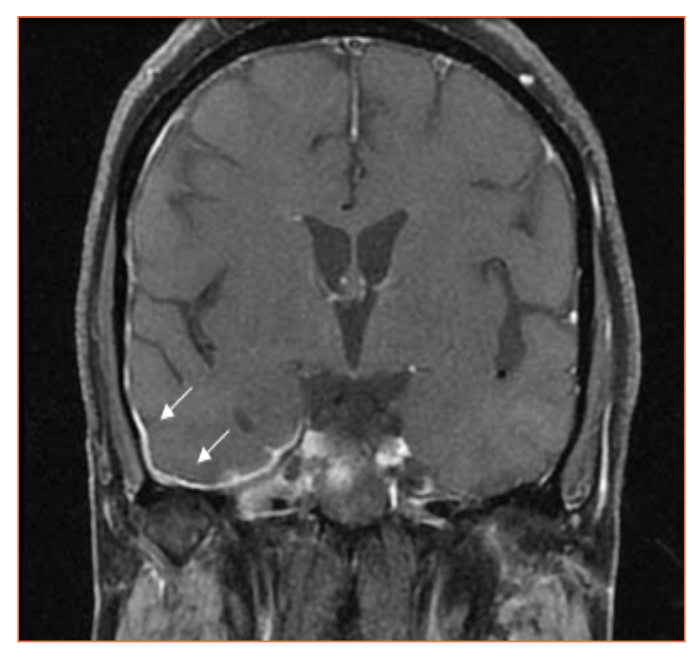

Figure 2. MRI of brain sagittal view.

\section{CONCLUSION}

Pachymeningitis is a rare manifestation in lgG4-related disease. There are no case reports in the literature of this disease associated with SLE. In this case, treatment with glucocorticoids was effective in resolving the symptoms. 